\title{
ORGANOMETALLIC CATALYSIS: SOME CONTRIBUTIONS TO ORGANIC SYNTHESIS ${ }^{\#}$
}

\author{
Elena V. Gusevskaya \\ Departamento de Química, Universidade Federal de Minas Gerais, CP 702, 31270-901 Belo Horizonte - MG
}

Recebido em 27/5/02; aceito em 28/8/02

\begin{abstract}
In the present paper some general aspects of metal complex catalysis and its applications for oxyfunctionalization of various
\end{abstract} olefins, including naturally occurring ones, via selective oxidation, hydroformylation and alkoxycarbonylation are discussed.

Keywords: catalysis; metal complexes; olefins.

\section{INTRODUCTION}

Synthetic chemicals are extremely important in all fields of our life and their cheap production in large amounts is necessary for the successful economic growth of modern civilization. Catalysis offers the unique possibility of fast and selective synthesis of desired chemical molecules without consumption of extra amounts of energy and theoretically without the consumption of catalyst itself. Presently, most of industrial chemical processes are based on catalysis. The steady replacement of classical stoichiometric methodologies with cleaner catalytic alternatives is also promoted by a growing environmental awareness and an increasing pressure on chemical industry to reduce a waste production. The amounts of waste (undesired products) produced per kilogram of product, designated as E factor, are especially high in the manufacture of fine chemicals (up to $100 \mathrm{~kg}$ ), while oil refining and bulk chemicals industry usually produce ca. 0.1 and $1-5 \mathrm{~kg}$ of by-products, respectively, per kilogram of product ${ }^{1,2}$. This situation is partly due to the use of multi-step syntheses in fine chemistry but also due to the predominant utilization of stoichiometric rather than catalytic methods. On the other hand, most of modern petrochemical technologies are one-step catalytic processes with high atom utilization ${ }^{1,2}$.

Transition metals have become an important instrument in organic synthesis due to their ability to activate organic substrates and promote various interactions between the ${ }^{3}$. A rapid progress in the study of organometallic and coordination compounds has led to the development and successful industrial application of a number of catalytic processes based on use of these compounds as catalysts ${ }^{4-6}$. The major advantage of organometallic catalysis that has led to its widespread adoption by industry is selectivity, the ability to produce pure products in high yield. The main reasons why transition metals contribute so essentially in catalysis are the follows: a) bonding ability: the ability to form both $\pi$ - and $\sigma$-bonds with other moieties; b) wide choice of ligands: transition elements readily form chemical bonds with almost every other element and almost any organic molecule; c) ligand effects: a ligand can influence the behavior of a transition metal catalyst by varying the steric or electronic environment at the active site; d) variability of oxidation state and co-ordination number; e) ability to readily interchanges between oxidation states during a catalytic reaction: transition metals can be readily involved in redox processes.

e-mail: elena@dedalus.lcc.ufmg.br

* Conferência proferida na $25^{\mathrm{a}}$ Reunião Anual da SBQ, Maio/2002, Poços de Caldas, MG
The mechanism of catalytic reactions promoted by transition metal complexes can be rationalized as a sequence of stoichiometric steps linked in a cyclic way thus forming a catalytic cycle. First, the formation of an organometallic compound occurs via the coordination or addition of substrate(s) to a metal center. That is followed by a series of intramolecular transformations of the activated substrate(s), which can involve also external groups and substrate(s), and the decomposition of the organometallic compound to give reaction products. Generally, metal complexes are changed as a result of such transformations and their regeneration is necessary to complete a catalytic cycle. Stoichiometric transformations involved in a catalytic process are the fundamental reactions of coordination and organometallic chemistry: ligand coordination, oxidative addition, insertion, isomerization, reductive elimination, etc.

No doubt much of the interest arises from the potential commercial importance of these reactions and for this reason, most of the earlier works were concerned with the preparative aspects of organometallic catalysis. However, during the last 30 years a considerable number of mechanistic works, including studies of the organometallic chemistry involved in catalytic reactions, appeared in the literature.

\section{PALLADIUM CATALYZED OXIDATION OF OLEFINS}

In the middle of the 1950s, a special interest of organic chemists to palladium arrose. One of the events that stimulated the development of the palladium organic chemistry was the discovery of a Wacker process in 1956 by a German research team ${ }^{7}$ and its further industrial application. Presently about 1.5 million tones of acetaldehyde per year are produced from ethylene and oxygen using $\mathrm{PdCl}_{2} / \mathrm{CuCl}_{2}$ as the catalyst. In 1894, Phillips reported ${ }^{8}$ that aqueous palladium chloride was reduced to palladium metal by ethylene. A great contribution of the Wacker group was the invention of the catalytic process by the addition of cupper(II) chloride to re-oxidize palladium thus allowing the use of the noble metal in catalytic amounts. Reduced copper complexes are readily re-oxidized by dioxygen.

Since that discovery, palladium has been introducing to modern chemistry resulting in important changes in organic synthesis. Due to a great number of the developed oxidative processes promoted by palladium complexes, this element has become one the most frequently used in organic transformations transition metals. Stoichiometric in palladium reactions may be incorporated into catalytic processes using reversible oxidants. Scheme 1 represents a catalytic cycle for the oxidation of organic substrate, e.g., olefin, by dioxygen promoted by a two-component catalytic system "palladium/ 
reversible oxidant". Complexes of $\mathrm{Cu}(\mathrm{II}), \mathrm{Fe}(\mathrm{II})$, heteropoly acids and benzoquinone are commonly used as reversible oxidants in these systems. In the case of benzoquinone, the re-oxidation of its reduced form, i.e. hydroquinone, is a slow reaction, which can be accelerated by the addition on a third component into the catalytic system, e.g., some cobalt complexes or heteropoly acids ${ }^{9-11}$.

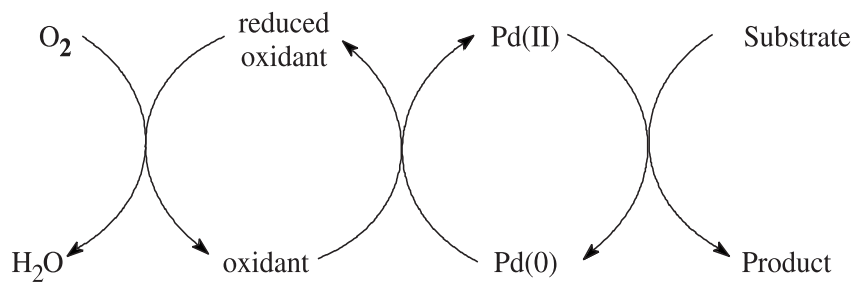

$$
\text { Substrate }+1 / 2 \mathrm{O}_{2} \quad \stackrel{\mathrm{Pd}(\mathrm{II})}{\stackrel{\begin{array}{c}
\text { reversible } \\
\text { oxidant }
\end{array}}{\longrightarrow}} \text { Product }
$$

Scheme 1. Palladium catalyzed oxidation with dioxygen

An alternative final oxidant for palladium catalyzed organic oxidations is hydrogen peroxide: a cheap and environmentally friendly reagent, with water being formed as the only by-product (Scheme 2). There are relatively little information in the literature concerning the use of hydrogen peroxide as a palladium re-oxidant in Wacker-type processes ${ }^{12,13}$. The introduction of benzoquinone exerts a beneficial effect in these systems ${ }^{14,15}$, probably due to the formation of palladium-benzoquinone complexes.

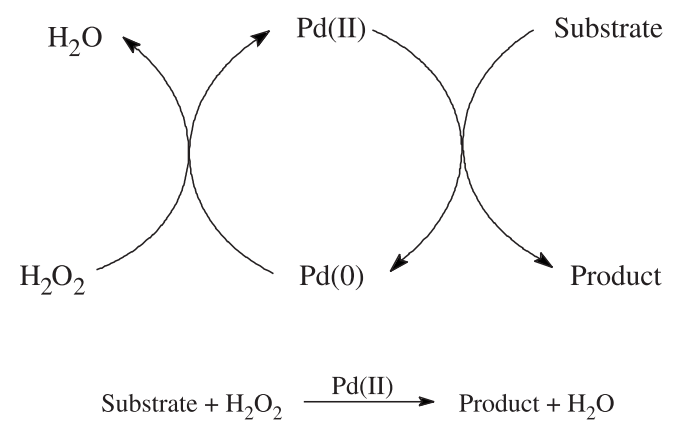

Scheme 2. Palladium catalyzed oxidation with hydrogen peroxide

In multi-component catalytic systems, re-oxidants frequently interfere in the mechanism of the olefin oxidation and can even change a product distribution. It is especially probable for coordinating reoxidants. Re-oxidants are originally introduced to palladium-based catalytic systems to simply re-oxidize the reduced palladium species and, according to Scheme 1, should not influence the step of the palladium-olefin interaction, which determines a product nature. However, there were published some observations showing that such an influence cannot be disregarded.

The main products of $\alpha$-olefin oxidation by $\operatorname{Pd}(\mathrm{II})$ salts in water and acetic acid solutions are carbonyl compounds and vinyl ethers, respectively. In 1964, Clement et al. ${ }^{16}$ found that the introduction of $\mathrm{CuCl}_{2}$ (as re-oxidant) in high concentrations completely changed the reaction route: glycol derivatives (acetates and chlorohydrines) were mainly formed. M. Tamura ${ }^{17}$ observed that the use of $\mathrm{LiNO}_{3}$ for the reoxidation of palladium in acetic acid also led to the formation of exclusively glycol acetates from $\alpha$-olefins. Later, some other examples of such a behavior were reported ${ }^{18,19}$. All early explanations of the influence of copper chloride on the reaction mechanism were based only on the analysis of the product composition ${ }^{19}$. We clarified a nature of this effect by the detailed kinetic and spectroscopic study of propylene oxidation in the $\mathrm{PdCl}_{2} / \mathrm{CuCl}_{2} / \mathrm{HOAc}$ system using UVVIS, EPR and NMR spectroscopy ${ }^{20}$. Under the reaction conditions, the heteronuclear bridging $\mathrm{Pd}-\mathrm{Cu}$ complexes and adducts between $\pi$-olefin palladium complexes and copper(II) ions have been detected (Scheme 3). Due to the insertion of olefin into the Pd-O bond a $\sigma$ organopalladium intermediate is formed. The presence of copper in this intermediate favors its decomposition not via a $\beta$-hydride shift, which would lead to acetone, but via a heterolysis of the $\mathrm{Pd}-\mathrm{C}$ bond (much less common for alkyl palladium compounds with $\beta$ hydrogens) resulting in a highly valuable glycol acetate.

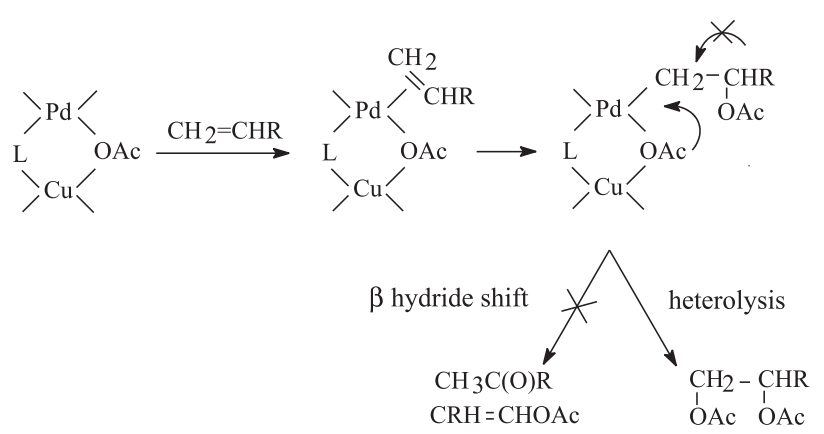

Scheme 3. Palladium-copper catalyzed oxidation of olefins with dioxygen into glycol derivatives

Some oxygen-containing re-oxidants may also serve as oxygen sources for the product formation. If the reduced form of the reoxidant can be re-oxidized back by dioxygen, then this re-oxidant acts as the agent of oxygen transfer from dioxygen to olefin. Nitrite and nitrate anions are among such re-oxidants. $\mathrm{Pd}(\mathrm{II}) / \mathrm{NO}_{3}{ }^{-}$catalytic systems in some cases offer valuable alternatives to the Wacker catalyst ${ }^{21-31}$. Products in these systems are formed as a result of the interaction between re-oxidant and olefin both coordinated on palladium. Thus, studies of the mechanisms of stoichiometric reactions of olefin oxidation by palladium complexes with nitro and nitrato ligands are of a great interest for the elucidation of the mechanisms of catalytic reactions.

We synthesized a series of nitro and nitrate palladium(II) complexes with a generalized formula $\mathrm{Pd}\left(\mathrm{NO}_{\mathrm{n}}\right)_{\mathrm{m}} \mathrm{Cl}_{2-\mathrm{m}}\left(\mathrm{CH}_{3} \mathrm{CN}\right)_{2}$, where $\mathrm{n}=2,3 ; \mathrm{m}=0,1,2$; and studied their reactivity in the oxidation of various olefins ${ }^{24-26,29-31}$. The interaction of olefins with these complexes depends on the olefin nature, number of $\mathrm{N}$-containing ligands on palladium and solvent. The interaction with acyclic olefins can result in aldehydes, ketones, 1,1-disubstituted alkanes, glycol derivatives and vinyl ethers ${ }^{24,30}$. For cyclic olefins and methylenecycloalkanes, the product nature is much more variable since their oxidation by palladium can be accompanied by skeletal rearrangements resulting in the formation of ring-expanded, ring contracted or ring-opened products ${ }^{25,26,29,31}$.

We studied the mechanism of these reactions by NMR and IR spectroscopy in situ. The reactions were performed directly in NMR tubes at low temperatures (down to $250 \mathrm{~K}$ ) in order to stabilize organopalladium intermediates and in special cells of IR spectrometers. Simultaneously with the registration of ${ }^{1} \mathrm{H}$ and ${ }^{13} \mathrm{C}$ NMR spectra during the olefin transformation into reaction products, the changes in nitrogen-containing fragments were monitored by IR 
spectroscopy. Various organopalladium compounds with the dynamics characteristic for intermediates have been detected and monitored in situ, mostly for the first time, and their structure and reactivity have been studied. Based on obtained data the detailed mechanisms of various processes were suggested.

Even in the case of the most simple olefin, i.e., ethylene, a great variety of products can be formed: the products of 1,1-addition (acetaldehyde and 1,1-disubstituted ethanes) and 1,2-addition (glycol monoacetate) to the double bond as well as vinylic derivatives (vinyl acetate and nitroethylene). The study of the organometallic chemistry involved allowed us to generalize the mechanism of the formation of all these products ${ }^{24}$. The key reaction intermediates - $\sigma$ organopalladium compounds formed via the insertion of coordinated ethylene into Pd-O or Pd-N bonds - have been observed in situ by both NMR and IV (Scheme 4). The nature of oxidation products is determined in the step of the decomposition of these $\sigma$-akyl palladium complexes. Scheme 5 shows the reaction routes leading to 1,1addition products and vinyl ethers. In particularly, for the first time we registered the organometallic precursor of acetaldehyde $\left(\mathrm{Pd}-\mathrm{CH}_{2}-\right.$ $\mathrm{CHO}$ ), which is, in fact, the intermediate of the $\beta$-hydride shift (later, we observed similar species for other olefins). Various intermediates responsible for the formation of glycol monoacetate have also be detected, e.g., the product of the acetoxypalladation of ethylene and the palladium complex with a hydroxyalkyl ligand and coordinated acetyl nitrite (or nitrate) shown in Scheme 6. The decomposition of the latter via a heterolysis of the Pd-C bond under the action of the coordinated acetyl nitrite (nitrate) gives glycol monoacetate and a nitrosyl palladium complex. In the absence of $\mathrm{N}$-ligand, the palladium-hydroxyalkyl intermediate decomposes via the $\beta$-hydride shift resulting in acetaldehyde. Thus, it was understood the beneficial effect of nitrate ions, originally used as re-oxidants for the reduced palladium species, on the nature of the product of olefin oxidation by dioxygen catalyzed by $\mathrm{Pd}(\mathrm{II})$.

The applications of the $\mathrm{Pd}(\mathrm{II}) / \mathrm{NO}_{3}^{-}$catalytic systems have been extended in our further works to small ring cycloalkenes and methylenecycloalkanes ${ }^{25,26}$ as well as to monoterpenes ${ }^{29,30}$.

Then we tried to develop a heterogeneous version of the $\mathrm{Pd}(\mathrm{II}) /$ $\mathrm{NO}_{3}^{-}$catalytic system, which showed a high activity in the oxidation of various olefins, in order to facilitate the step of the catalyst separation from reaction products. We have developed the oxidative acetoxylation of propylene into glycol acetate over Pd, Pd-Pt, and $\mathrm{Pt}-\mathrm{Rh}$ catalysts supported on carbon, $\mathrm{SiO}_{2}$, and $\mathrm{TiO}_{2}$ in acetic acid

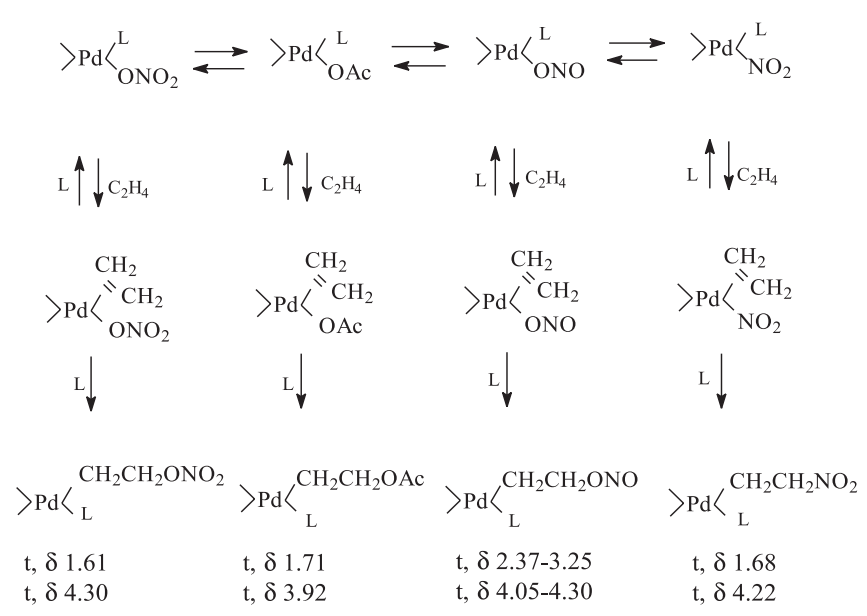

Scheme 4. Formation of $\sigma$-organopalladium intermediates at ethylene oxidation

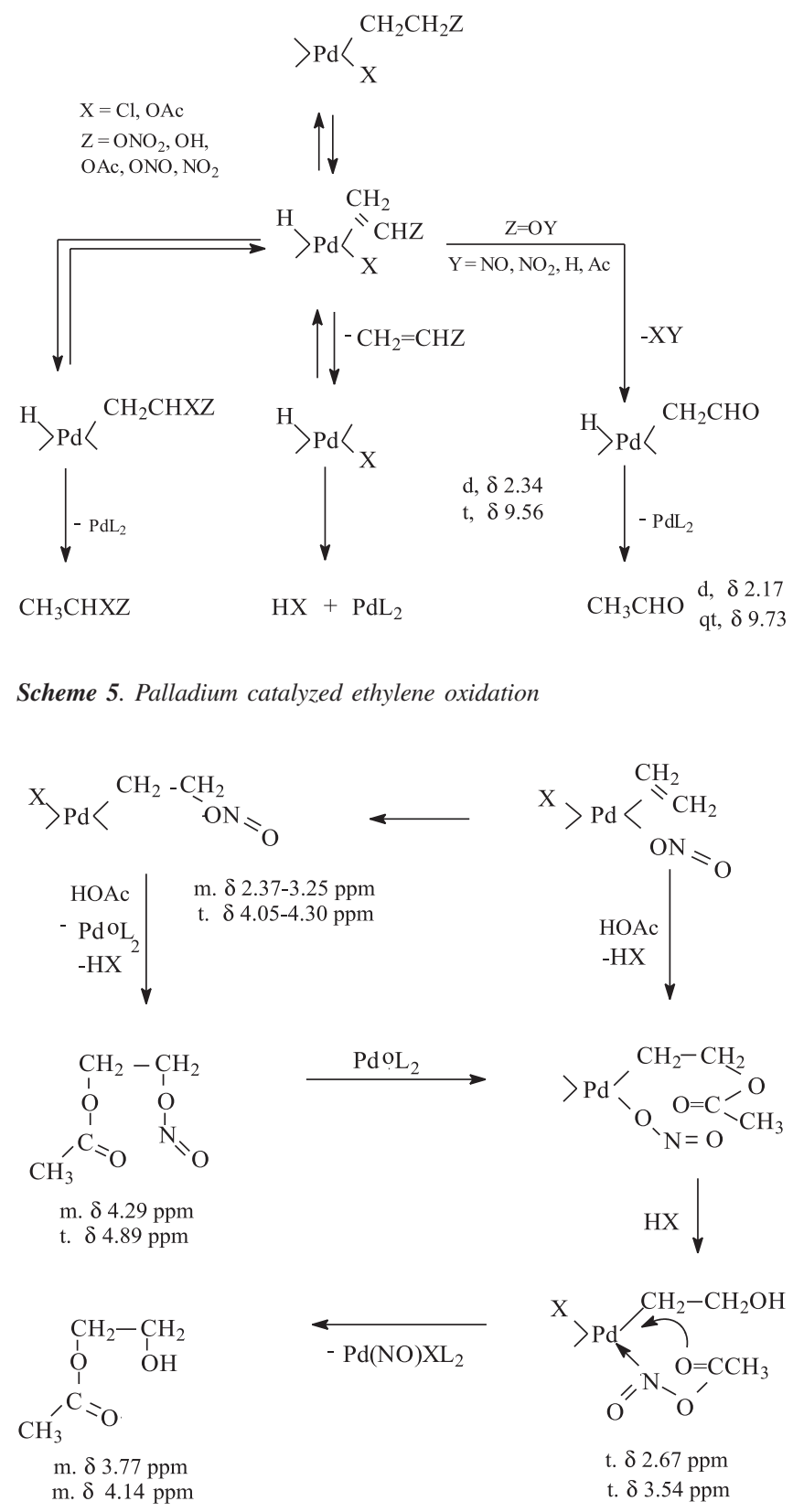

Scheme 6. Palladium catalyzed ethylene oxidation

solutions of nitric acid $\mathrm{a}^{27,28,32}$. Palladium catalysts on carbon exhibit a high activity and an ca. $90 \%$ selectivity, while monometallic platinum and rhodium catalysts show no activity. Propylene oxidation proceeds both on the catalyst surface and in the solution due to the palladium leaching. After the reaction, the catalyst can be regenerated at mild conditions. The treatment of the suspension with hydrogen results in the reduction of the dissolved palladium(II) complexes and the deposition of the palladium metal back on the support. After filtration, the catalyst can be used again for propylene oxidation.

We supposed that the addition of components that serve as hydrogen activators, such as platinum or rhodium, could improve the efficiency of the reductive regeneration and catalyst stability. Indeed, $\mathrm{Pd}-\mathrm{Pt} / \mathrm{C}$ catalysts show a high activity for 15 oxidationregeneration cycles, while the activity of $\mathrm{Pd} / \mathrm{C}$ and $\mathrm{Pd}-\mathrm{Rh} / \mathrm{C}$ catalysts is maintained only for 3-4 cycles. This work has become a basis for a new technology, which we developed and patented for the synthesis of propylene oxide ${ }^{32,33}$. 
Propylene oxide is a key intermediate in the production of polyurethanes and polyesters and currently produced by non-catalytic methods via chlorohydrin or by propylene epoxidation with hydroperoxide, both suffering from heavy waste problems. We developed a new process ${ }^{27,33}$ for the propylene oxide synthesis from propylene and dioxygen in two steps: 1) oxidation of propylene into propylene glycol monoacetate using Pd, Pd-Pt and Pd-Rh supported catalysts and 2) cracking of propylene glycol monoacetate into propylene oxide and acetic acid (which is recycled) in a flow reactor containing a melt of potassium acetate as catalyst.

\section{METAL COMPLEX CATALYZED FUNCTIONALIZATION OF NATURALLY OCCURRING OLEFINS}

Selective functionalization of sufficiently abundant monoterpenes represents a promising route for the valorization of these cheap natural products. Some of their oxygenated derivatives (alcohols, aldehydes, ketones, allylic ethers, carboxylic acid esters) are commercially important materials for pharmaceutical, flavor, and perfumery industries as well as useful synthetic intermediates and chiral building blocks ${ }^{34,35}$. These compounds can be produced from olefins by metal catalyzed selective oxidation and carbonylation of their double bonds ${ }^{3-6,18,19}$. Because of its commercial importance the olefin oxidation by palladium(II) salts has received the most considerable attention, especially when such environmentally friendly and low-priced oxidants as dioxygen and hydrogen peroxide are involved $^{18,19,36}$. Although these reactions have been developed into important synthetic methods, there is very little information in literature concerning their application to natural product synthesis. The other important pathways for the synthesis of oxygen-containing derivatives of monoterpenes are metal catalyzed carbonylation, i. e., alkoxycarbonylation and hydroformylation. We have, in recent years, been studying the selective oxidation and carbonylation of monoterpenes, such as limonene (1), $\alpha$-pinene (2), $\beta$-pinene (3) and camphene (4), via homogeneous catalysis by metal complexes. In the present paper, some recent results in this field are presented.

\section{Palladium catalyzed oxidation of monoterpenes by dioxygen}

We have investigated the use of the "Pd(II)+reversible re-oxidant $\left(\mathrm{CuCl}_{2}\right.$ or $\left.\mathrm{LiNO}_{3}\right)$ " catalytic systems for the oxidation of monoterpenes, such as limonene, camphene, $\alpha$-pinene and $\beta$-pinene, with dioxygen ${ }^{15,29,30,37}$. Acetic acid solutions of limonene (1) containing $\mathrm{PdCl}_{2}, \mathrm{CuCl}_{2}$ and $\mathrm{LiCl}$ rapidly consumed dioxygen at 60 $80{ }^{\circ} \mathrm{C}$ and $0.1 \mathrm{MPa}^{37}$. Allylic oxidation of limonene into carveyl acetate $(\mathbf{5}, 85 \%$ trans $)$ and carvone $(\mathbf{6})$ was observed as a main reaction (Scheme 7), along with its isomerization into $\alpha$-terpinolene (10) and $\gamma$-terpinene (11) and an $\mathrm{HOAc} / \mathrm{H}_{2} \mathrm{O}$ addition resulting in a-terpenyl acetate (7) and $\alpha$-terpineol (8) (Scheme 8).<smiles>C=C(C)C1CC=C(C)CC1</smiles>

1

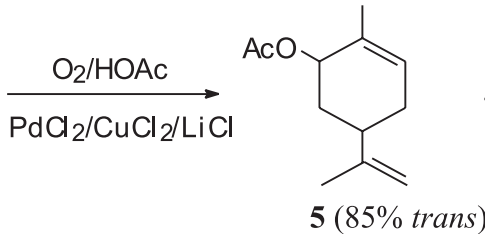

$5(85 \%$ trans $)$

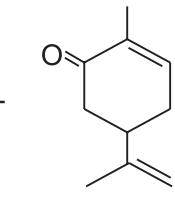

6
Scheme 7. Oxidation of limonene by dioxygen

Both addition and isomerization reactions are reversible, with no allylic oxidation of $7,8,10$ and 9 , which contain no terminal

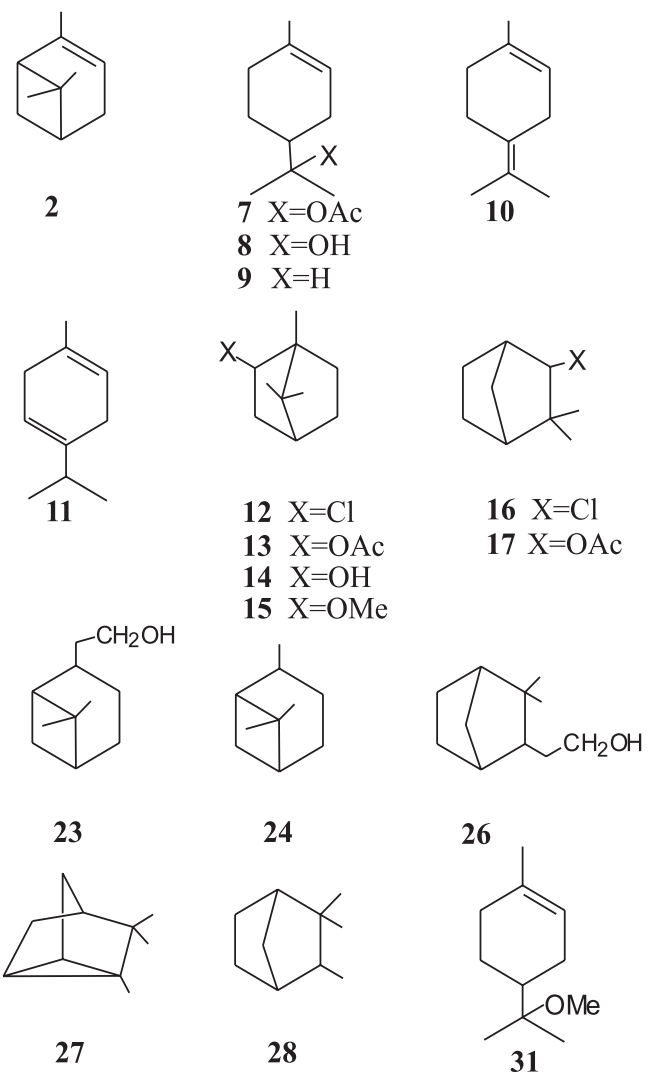

Scheme 8. Derivatives of monoterpenes

double bond, being observed. A $\pi$-allyl palladium complex was suggested as a reaction intermediate, with the coordination of the exocyclic double bond on the same palladium atom being of a critical importance for its reactivity: e.g., carvomenthene (9) undergoes no allylic oxidation even at high temperature ${ }^{37-39}$. The isomerization and addition equilibria are shifted towards the formation of $\mathbf{1}$ at higher conversions, thus, the selectivities for $\mathbf{5}$ and $\mathbf{6}$ rise significantly with the reaction time. Under the optimized conditions a $90 \%$ conversion and $96 \%$ combined selectivity for $\mathbf{5}$ and $\mathbf{6}$ were obtained.We have found that the rate of the allylic oxidation of limonene is the first order in copper concentration. This observation indicates that $\mathrm{CuCl}_{2}$ has behavior far exceeding that of a simple re-oxidant. We have supposed that one of the specific functions of $\mathrm{CuCl}_{2}$ is to assist at the decomposition of the $\pi$-allyl Pd intermediate due to the formation of bridging $\mathrm{Pd}-\mathrm{Cu}$ complexes.

The reactions of $\alpha$-pinene (2) and $\beta$-pinene (3) under similar conditions result in a mixture of 5 (ca. 25\%), 7 (ca. 25\%), bornyl chloride (12) (ca. 30\%), and fenchyl chloride (16) (ca. 15\%) $)^{37}$. Camphene (4) also undergoes a skeletal rearrangement and an acetic $\mathrm{acid} /$ water addition resulting in bornyl acetate (13) and borneol (14) as major products ${ }^{15}$. The results obtained show that the application of the $\mathrm{PdCl}_{2}-\mathrm{CuCl}_{2}$ system for the oxidation of bicyclic monoterpenes is limited, since $\mathrm{CuCl}_{2}$, acting as a Lewis acid, promotes undesirable non-oxidative skeletal isomerizations. We concentrated our efforts on developing a $\mathrm{CuCl}_{2}$-free catalyst. The activity of the $\mathrm{Pd}(\mathrm{OAc})_{2}^{-}$ $\mathrm{LiNO}_{3}$ system has been studied ${ }^{15,37}$. Although nitrate ions readily reoxidize reduced palladium species and are reoxidized back by dioxygen, no formation of oxidation products in significant amounts are observed for limonene, $\alpha$-pinene and $\beta$-pinene. In the case of camphene, however, highly selective oxidative processes occur in the presence of this catalytic system ${ }^{29,30}$. 


\section{Palladium catalyzed oxidation of monoterpenes by hydrogen peroxide}

We have found that some monoterpenes can be selectively oxidized by $\mathrm{H}_{2} \mathrm{O}_{2}$ using $\mathrm{Pd}(\mathrm{OAc})_{2}$ as the catalyst in $\mathrm{HOAc} / \mathrm{H}_{2} \mathrm{O}$ solutions in the absence of halogens and co-metals, with the olefin structure greatly influencing the product nature ${ }^{15}$. $\beta$-pinene gives the allylic oxidation products, i.e., pinocarveol (18), pinocarveyl acetate (19), and myrtenyl acetate (20), with selectivity up to $75 \%$ at virtually complete conversion of $\mathbf{3}$ (Scheme 9). A competing skeletal isomerization and solvent addition yield various by-products, the major of them being $\mathbf{7}$, along with $\mathbf{1 3}, \mathbf{8}$, and bornyl acetate (17).<smiles>C=C1CC2CCC1C2(C)C</smiles>

3

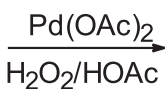

$\mathrm{H}_{2} \mathrm{O}_{2} / \mathrm{HOAC}$

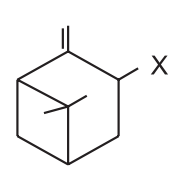

$18 \mathrm{X}=\mathrm{OH}$

$19 \mathrm{X}=\mathrm{OAc}$

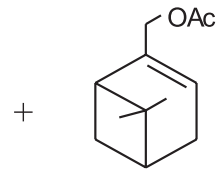

20
Scheme 9. Oxidation of $\beta$-pinene by hydrogen peroxide

Camphene (4), which has the only and not easily abstractable allylic hydrogen at a bridgehead position, gives camphene glycol monoacetate $\mathbf{2 1}$ (Scheme 10) with ca. $90 \%$ selectivity at $80 \%$ substrate conversion. The introduction of benzoquinone (BQ) in catalytic amounts up to $\mathrm{BQ} / \mathrm{Pd}=10$ exerted a beneficial effect on the catalyst stability and selectivity. Product $\mathbf{2 1}$ was not detected at all if palladium acetate was excluded, therefore, its formation cannot be explained by a non palladium-centered epoxidation of camphene by the peroxyacetic acid generated in situ followed by ring opening of epoxide by acetic acid.<smiles>C=C1C2CCC(C2)C1(C)C</smiles>

4

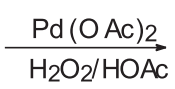

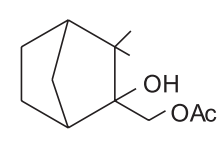

21
Scheme 10. Oxidation of camphene by hydrogen peroxide

The palladium catalyzed acetoxylation of $\beta$-pinene and camphene in aqueous acetic acid solutions containing hydrogen peroxide can be seen as a nucleophilic attack by three nucleophiles, i.e., $\mathrm{H}_{2} \mathrm{O}_{2}$, $\mathrm{H}_{2} \mathrm{O}$ and HOAc, on the olefin coordinated to palladium in a $\pi$ - (for camphene) or $\pi$-allylic (for $\beta$-pinene) mode. The nature of reaction products depends strongly on the coordination mode, which, in turn, is determined by the olefin structure. The allylic derivatives of $\beta$ pinene 18-20 appear to be formed via the nucleophilic attack of the acetate group on a ( $\pi$-allyl)-palladium intermediate, whereas glycol acetate 21 via hydroxy- or peroxypalladation of olefin in a $\pi$ camphene-palladium complex (Scheme 11)

Without the oxidizable substrates hydrogen peroxide decomposes with palladium acetate, but this decomposition is fairly slow with respect to palladium-catalyzed oxidation of $\beta$-pinene and camphene. No selective oxidation of limonene and $\alpha$-pinene was observed under similar conditions ${ }^{15}$.

\section{Platinum/tin catalyzed hydroformylation of monoterpenes}

Hydroformylation represents a versatile method for the production of commercially important aldehydes and alcohols, which are difficult to obtain by conventional synthetic pathways. A number of monoterpenes ${ }^{40-42}$ have been hydroformylated, in the presence of cobalt and rhodium complexes, which are most commonly used to catalyze this reaction in industrial processes. Most of the cobalt and rhodium catalysts promote a significant undesirable isomerization of $\beta$-pinene to $\alpha$-pinene. Among the alternative catalytic systems, those based on platinum/tin compositions are probably the most promising ones, as these systems allow high regioselectivity for the formation of linear aldehydes and are especially efficient in asymmetric reactions. However, their applications to monoterpenes are scarcer ${ }^{43-46}$.

We studied the hydroformylation of $\beta$-pinene (Scheme 12) using rhodium complexes and various phosphines and diphosphines as auxiliaries ${ }^{47}$. For all catalytic systems, a significant formation of $\alpha$ pinene 2 occurs, with the ratio between the trans and cis isomer of 10-formylpinane $\mathbf{2 2}$ depending on the auxiliary nature, temperature and $\mathrm{Rh} / \mathrm{P}$ ratio. Cis isomer 22a is preferentially formed in all promoted systems $(60-85 \%)$.

In the presence of the $\mathrm{PtCl}_{2} \mathrm{P}_{2} / \mathrm{SnCl}_{2} / \mathrm{PPh}_{3}$ systems $\left(\mathrm{P}=\mathrm{PPh}_{3}, \mathrm{P}_{2}=\right.$ dppe, dppp, and 1,4-bis(diphenylphosphino)butane (dppb)), hydroformylation of limonene (1), $\beta$-pinene (3), and camphene (4) proceeds regiospecifically resulting exclusively in linear aldehydes (Schemes 12-14). The hydroformylation of $\mathbf{3}$ yields trans-isomer $\mathbf{2 2 b}$ with a $98 \%$ diastereoisomeric excess (d.e.), while $\mathbf{1}$ and $\mathbf{4}$ give the diastereoisomeric mixtures of aldehydes 29 and 25 (d.e. of ca. 10 and

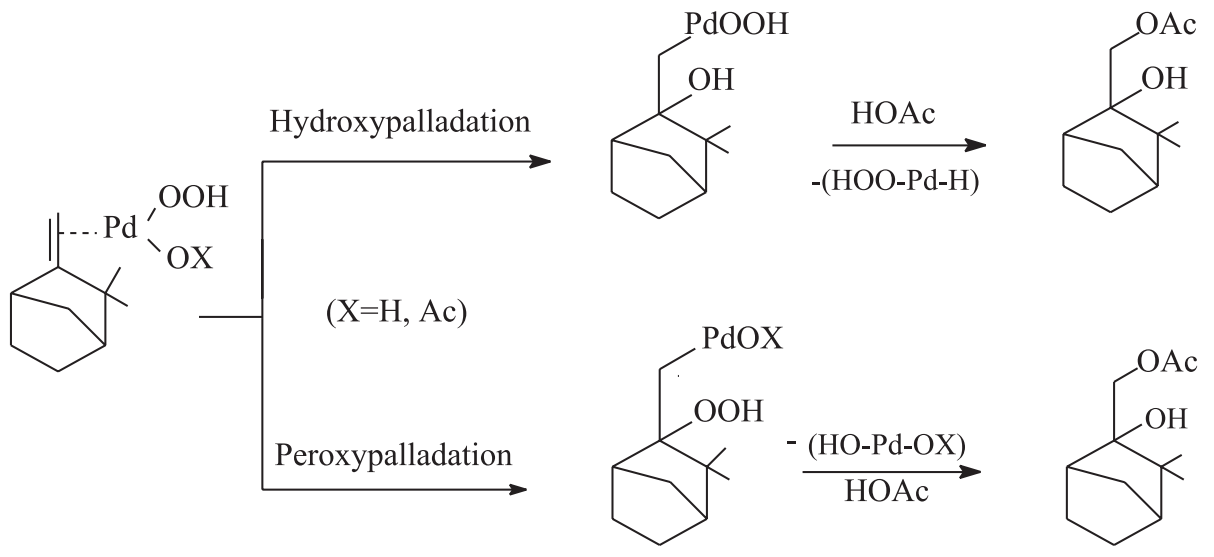




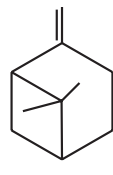

3
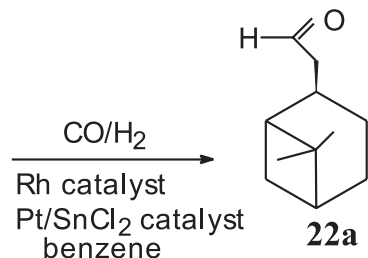

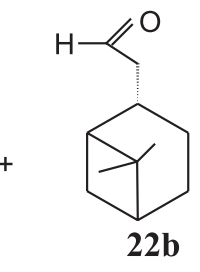

Scheme 12. Hydroformylation of $\beta$-pinene

$15 \%$, respectively). Differently from most of the cobalt and rhodium catalysts, the isomerization of $\beta$ - into $\alpha$-pinene is slow (1-5\% on reacted 3). Concurrent transformations of monoterpenes and primarily formed aldehydes occur: hydrogenation of substrates (into pinane (24), isocamphane (28), and 9) and aldehydes (into alcohols 23 and 26), substrate isomerizations which can be accompanied by a nucleophilic addition (giving $\mathbf{2}$, tricyclene (27), 10-12, and 16), etc. Under optimized conditions, chemoselectivities for aldehydes of near $90 \%$ have been attained for all monoterpenes studied, however, d.e. for $\mathbf{2 5}$ is low in all systems with achiral ligands. Asymmetric hydroformylation of $\mathbf{4}$ in up to $60 \%$ d.e. has been achieved with $\mathrm{PtCl}_{2}(\mathrm{PhCN})_{2} / \mathrm{SnCl}_{2} /$ diphosphine catalysts containing chiral diphosphines such as (R)-(+)-binap (2,2'bis(diphenylphosphino)-1,1'-binaphthyl) ${ }^{48}$.

Under hydroformylation conditions limonene can be converted in one pot into bicyclic alcohol 30, useful as perfume, employing the $\mathrm{PtCl}_{2}(\mathrm{dppb}) / \mathrm{PPh}_{3} / \mathrm{SnCl}_{2}$ bifunctional catalyst, which promotes both the hydroformylation of $\mathbf{1}$ and then the stereospecific intramolecular cyclization of menthene $(\mathbf{2 9})^{45}$. At $130{ }^{\circ} \mathrm{C}, \mathbf{3 0}$ becomes the dominant product (ca. $82 \%$ selectivity at $95 \%$ conversion). High selectivities for $\mathbf{2 9}$ can be attained at lower conversions. In the absence of either a platinum complex or $\mathrm{SnCl}_{2}$, no cyclization of $\mathbf{2 9}$ is observed, thus the heterobimetallic platinum-tin species seems to be involved in this reaction.

\section{Palladium/tin catalyzed alkoxycarbonylation of monoterpenes}

Metal complex catalyzed alkoxycarbonylation represents another valuable route for the functionalization of monoterpenes which provides directly carboxylic acid derivatives. We used the $\mathrm{PdCl}_{2} \mathrm{P}_{2} /$ $\mathrm{SnCl}_{2} / \mathrm{PPh}_{3}$ systems as catalysts for alkoxycarbonylation of monoterpenes $\left(\mathrm{P}=\mathrm{PPh}_{3}, \mathrm{P}_{2}=\mathrm{dppe}, \mathrm{dppp}, \mathrm{dppb}\right)^{49}$. Limonene gives mainly linear ester 32 (ca. 90\%) along with 10, 11 and methanol addition product 31, while in the absence of $\mathrm{SnCl}_{2}$, branched ester 33 is also formed (ca. 10\%) (Scheme 14). The reaction of b-pinene yields exclusively the products of the Lewis acid catalyzed skeletal rearrangement/nucleophilic addition $(\mathbf{1}, \mathbf{2}, \mathbf{9 - 1 2}, \mathbf{1 6})$. No products of $\mathrm{CO}$ incorporation were observed. Camphene can be converted into linear ester $34(\mathbf{3 4 a} / \mathbf{3 4 b} \approx 1 / 1)$ with a $90 \%$ chemoselectivity and virtually $100 \%$ regioselectivity (linear/branched esters) (Scheme 13). Methyl bornyl ether $\mathbf{1 5}$ is the only major by-product. $\mathrm{SnCl}_{2}$ and $\mathrm{PdCl}_{2}\left(\mathrm{PPh}_{3}\right)_{2}$ exhibit a strong synergetic effect on the camphene alkoxycarbonylation. $\mathrm{PdCl}_{2}\left(\mathrm{PPh}_{3}\right)_{2}$ alone shows a very low catalytic activity promoting the predominant formation of thermodynamically more stable exo isomer $\mathbf{3 4 b}(\mathbf{3 4 a} / \mathbf{3 4 b} \approx 1 / 2)$.

It is surprising the difference in reactivity between camphene and $\beta$-pinene considering the similarity of these olefins. This difference could be related with the facility of $\beta$-pinene for the formation of $\pi$-allyl complexes with palladium(II), which are carbonylated at a much slower rate. The only allylic hydrogen in the molecule of camphene is at a tertiary carbon atom and not easily abstractable. So, the interaction of camphene with a palladium(II) hydride leads to the formation of a $\pi$-olefin complex followed by hydride addition. The stereochemistry of the ester is determined by the mode of camphene coordination to the palladium atom. In the presence of a sterically demanding $\mathrm{SnCl}_{3}{ }^{-}$ligand, the preferred coordination is through the less hindered "top" face of camphene resulting in ester 34a. In the absence of $\mathrm{SnCl}_{2}$, exo isomer $\mathbf{3 4 \mathbf { b }}$ is predominantly formed, which implicates the camphene coordination on the more crowded "bottom" face.
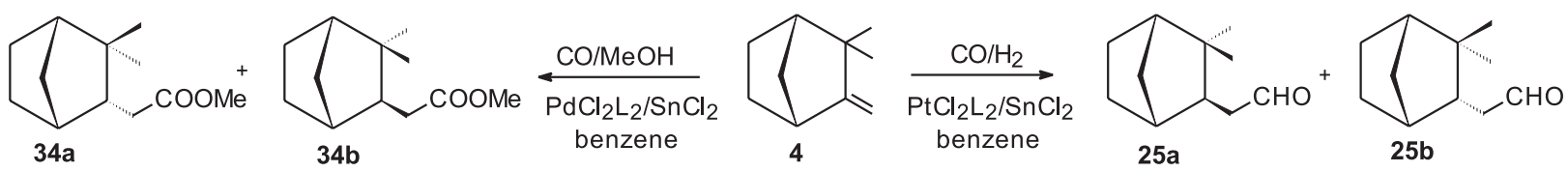

Scheme 13. Hydroformylation and alkoxycarbonylation of camphene

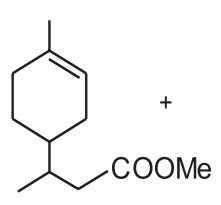

32<smiles>COC(=O)C(C)(C)C1CC=C(C)CC1</smiles>

33

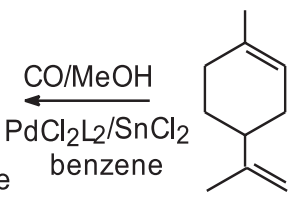

1

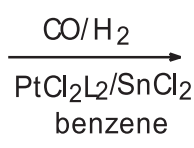

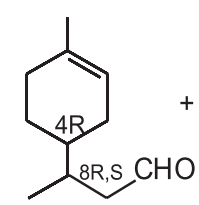

29

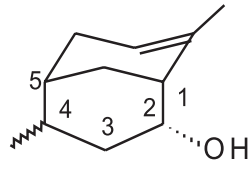

$30 \mathrm{a}-(1 \mathrm{R}, 2 \mathrm{R}, 4 \mathrm{~S}, 5 \mathrm{R})$

$30 \mathrm{~b}-(1 \mathrm{R}, 2 \mathrm{R}, 4 \mathrm{R}, 5 \mathrm{R})$

Scheme 14. Hydroformylation/cyclization and alkoxycarbonylation of limonene

\section{CONCLUSIONS}

Organometallic catalysis offers excellent opportunities for organic synthesis, especially for the synthesis of fine chemicals. Transition metals have a very rich organic chemistry and promote a great number of organic transformations including unconventional ones. The exceptional specificity of their action and functional group tolerance allow a flexibility in the choice of starting material and permit to develop environmentally benign catalytic processes with high atom utilization. The applications of organometallic catalysis was shown to be very promising routes for the selective oxyfunctionalization of low-priced naturally occurring monoterpenes, which are useful as substrates for the production of monoterpenoid flavors and fragrances. Various allylic acetates, alcohols, aldehydes, ketones and esters can 
be obtained in good yields and in some cases with high stereoselectivity by catalytic oxidation, alkoxycarbonylation, hydroformylation, hydration ${ }^{50}$ and acetoxylation ${ }^{50}$ of limonene, $\beta$ pinene, $\alpha$-pinene and camphene.

\section{ACKNOWLEDGMENTS}

I wish to express my sincere appreciation to my collaborators, whose names appear in the references, for their efforts in exploring the chemistry outlined in this review. Financial support from the CNPq, FAPEMIG, CAPES and PADCT is gratefully acknowledged.

\section{REFERENCES}

1. Sheldon, R.; Chem. Ind. 1992, 903.

2. Sheldon, R.; Pure Appl. Chem. 2000, 72, 1233.

3. Schlosser, M., ed., Organometallics in Synthesis; Wiley: New York, 1994.

4. Masters, C.; Homogeneous Transition-metal Catalysis: a Gentle Art, Chapman and Hall: New York, 1981.

5. Parshall, G. W.; Ittel, S. D.; Homogeneous Catalysis: the Applications and Chemistry of Catalysis by Soluble Transition Metal Complexes, Wiley: New York, 1992.

6. Cornils, B.; Hermann, W.A.; Applied Homogeneous Catalysis with Organometallic Compounds, Weinhein: New York, 1996.

7. Smidt, J.; Hafner, W.; Jira, R.; Sedtlmeier, J.; Sieber, R.; Ruttinger, R.; Koijer, H.; Angew. Chem. 1959, 71, 176.

8. Phillips, F. C.; Am. Chem. J. 1894, 16, 255

9. Grennberg, H.; Faison, S.; Backvall J.-E.; Angew. Chem., Int. Ed. 1993, $32,263$.

10. Grennberg, H.; Bergstad, K.; Backvall, J.-E.; Organometallics 1998, 17, 45.

11. Yokota, T.; Fujibayashi, S.; Nishiyama, Y.; J. Mol. Catal. A: Chem. 1996, $114,113$.

12. Moiseev, I. I.; Vargaftik, M. N.; Syrkin, Y. K.; Dokl. Akad. Nauk SSSR 1960, 133, 337.

13. Roussel, M.; Mimoun, H.; J. Org. Chem. 1980, 45, 5387.

14. Jia, C.; Muller, P.; Mimoun, H.; J. Mol. Catal. A: Chem. 1995, 101, 127.

15. Gusevskaya, E. V.; Robles-Dutenhefner, P. A.; Ferreira, V. M. S.; Appl. Catal. 1998, 132, 213.

16. Clement, W. H.; Selwits, C. M.; J. Org. Chem. 1964, 29, 241

17. Tamura, M.; Yasui, T.; Chem. Commun. 1969, 1209.

18. Heumann. A.; Jens. K.-J.; Réglier. M. In Progress in Inorganic Chemistry; Karlin, K. D., ed.; Wiley: New York, 1994, vol. 42, p. 483.

19. Henry, P.; Palladium-Catalyzed Oxidation of Hydrocarbons, Reidel: Dordrecht, 1980

20. Karandin, A. V.; Gusevskaya, E. V.; Likholobov, V. A.; Stepanov, A. G.; Talzi, E. P.; Kinet. Catal. 1990, 31, 506.

21. Andrews, M. A.; Chang, T. C.-T.; Cheng, C.-W. F.; Kelly, K. P.; Organometallics 1984, 3, 1777.

22. Chaulet, F.; Heumann, A.; Waegell, B.; J. Org. Chem. 1987, 52, 1916.

23. Kiers, N. H.; Feringa, B. L.; Tetrahedron Lett. 1992, 33, 2403.
24. Beck, I. E.; Gusevskaya, E. V.; Stepanov, A. G.; Likholobov, V. A.; J. Mol. Catal. A: Chem. 1992, 73, 115.

25. Beck, I. E.; Gusevskaya, E. V.; Golovin, A. V.; Likholobov, V. A.; J. Mol. Catal. A: Chem. 1993, 83, 287.

26. Beck, I. E.; Gusevskaya, E. V.; Golovin, A. V.; Likholobov, V. A.; J. Mol. Catal. A: Chem. 1993, 83, 300.

27. Karandin, A. V.; Gusevskaya, E. V.; Likholobov, V. A.; Kondratiev, V. A.; Markevitch, V. S.; Appl. Catal. A 1993, 97, 1.

28. Gusevskaya, E. V.; Likholobov, V. A.; Karandin, A. V.; Boronin, A. I.; Moroz, E. M.; Stud. Surf. Sci. Catal. 1996, 101(B), 1125.

29. da Silva, M. J.; Gusevskaya, E. V.; J. Mol. Catal. A: Chem. 2001, 176, 23.

30. Gusevskaya, E. V.; da Silva, M. J.; Anais de XVII Simpósio IberoAmericano de Catálise, Porto, Portugal, 2000.

31. Beck, I. E.; Golovin, A. V.; Gusevskaya, E. V.; Likholobov, V. A. In Catalysis and Catalysts. Fundamental Studies of the Boreskov Institute of Catalysis; Buyanov, R.A., ed.; CO PAH: Novossibirsk, 1998, p. 80.

32. Gusevskaya, E. V.; Karandin, A. V.; Likholobov, V. A.; Egorova, G. M.; Polovnikova, G. V.; Romanenko, A. V.; USSR pat. 14766811990 (CA 114:21557a)

33. Gusevskaya, E. V.; Karandin, A. V.; Likholobov, V. A.; Kondratiev, V. A.; Markevitch, V. S.; USSR pat. 14174381988.

34. Erman, W. E.; Chemistry of the Monoterpenes. An Encyclopedic Handbook, Marcel Dekker: New York, 1985.

35. Chalk, A. J.; Catalysis of Organic Reactions, Rylander, P. N.; Greenfield, H.; Augustine, R. L., eds.; Marcel Dekker: New York, 1988, vol. 22, p. 43.

36. Hegedus, L. S. In Organometallics in Synthesis; Schlosser, M., ed.; Wiley: New York, 1994, p. 383

37. Gusevskaya, E. V.; Gonsalves, J. A.; J. Mol. Catal. A: Chem. 1997, 121, 131.

38. El Firdoussi, L.; Benharref, A.; Allaoud, S.; Karim, A.; Castanet, Y; Mortreux, A.; Petit, F.; J. Mol. Catal. A: Chem. 1992, 72, L1.

39. El Firdoussi, L.; Baqqa, A.; Allaoud, S.; Allal, B. A.; Karim, A.; Castanet, Y.; Mortreux, A.; J. Mol. Catal. A: Chem. 1998, 135, 11.

40. Sirol, S.; Kalck, Ph.; New J. Chem. 1997, 21, 1129.

41. Azzaroni, F.; Biscarini, P.; Bordoni, S.; Longoni, G.; Venturini, E.; J. Organomet. Chem. 1996, 508, 59.

42. Soulantica, K.; Sirol, S.; Koinis, S.; Pneumatikakis, G.; Kalck, Ph.; J. Organomet. Chem. 1995, 498, C10.

43. Kollár, L.; Bakos, J.; Heil, B.; Sándor, P.; Szalontai, G.; J. Organomet. Chem. 1990, 385, 147.

44. Kollár, L.; Bódi, G.; Chirality 1995, 1, 121.

45. Dias, A. O.; Augusti, R.; dos Santos, E. N.; Gusevskaya, E. V.; Tetrahedron Lett. 1997, 38, 41.

46. Foca, C. M.; Dias, A. O.; Augusti, R.; dos Santos, E. N.; Gusevskaya, E. V.; J. Mol. Catal. A: Chem. 2000, 152, 15.

47. Barros, H. J. V.; Ospina, M. L.; Arguello, E.; Rocha, W. R.; Gusevskaya, E. V.; dos Santos, E. N.; J. Organomet. Chem., in press.

48. Foca, C. M.; dos Santos, E. N.; Gusevskaya, E. V.; J. Mol. Catal. A: Chem. 2002, 185,17 .

49. Rocha, L. L.; Dias, A. O.; Augusti, R.; dos Santos, E. N.; Gusevskaya, E. V.; J. Mol. Catal. A: Chem. 1998, 132, 213.

50. Robles-Dutenhefner, P. A.; da Silva, K. A.; Siddiqui, M. R. H.; Kozhevnikov, I. V.; Gusevskaya, E. V.; J. Mol. Catal. A: Chem. 2001, 175, 33. 